\title{
American Pediatric Society 2013 presidential address: 125th anniversary of the American Pediatric Society-lessons from the past to guide the future
}

\author{
Barbara J. Stoll ${ }^{1}$
}

This year is the 125th anniversary of the American Pediatric Society (APS), a time to reflect on the past 125 years of child health and child health research, a time to consider the health of America's children in a social and global context, and a time to consider the future. This paper is a combination of pediatric and APS history and personal story.

CHILD HEALTH AT THE TURN OF THE 20th CENTURY AND THE HISTORY OF THE APS

In the late $1880 \mathrm{~s}$, children were largely cared for by general practitioners, midwives, or respected women in the community. Few physicians in the United States cared solely for children, and even fewer were interested in studying diseases of children (1-6). Dr Job Lewis Smith has been called the "father of the APS." Appointed in 1861 as the first professor of pediatrics at Bellevue Hospital, he recognized that children were neglected by adult medicine and organized the first meeting of the APS in 1888. A relatively small group of physicians, interested in a more scientific approach to the study and practice of diseases of children, was invited to attend (2). The APS had 43 founding members. All were men. They were young, and half were from New York. Abraham Jacobi, one of the most distinguished pediatricians at the time, and the first professor of Pediatrics at Columbia, was elected APS's first president. Of note, the first woman member of APS, Dr Ethel Dunham, was not elected until 1928, 40 years after APS was founded. Dr Dunham had a very distinguished career, with an early focus on premature babies, and went on to be the first woman Howland awardee (2).

Our founders wrote that "the Society has for its object the advancement of the Physiology, Pathology, and Therapeutics of Infancy and Childhood." Throughout our 125 years, the APS has promoted the advancement of "scientific pediatrics"pediatric research, the training of physician scientists, and the practice of evidence-based medicine. The first scientific session was held in Washington, DC, in September 1888, with only four presentations (2). It is quite remarkable to consider how the APS and the field of pediatrics and pediatric research have grown. This year's Pediatric Academic Societies program has more than 4,500 presentations, including $\sim 1,500$ oral presentations. The first true scientific session of the APS was held the following year, with 25 attendees, who presented 27 papers. Most of the presentations were clinical studies with only a few patients.

Abraham Jacobi gave the first presidential address, "The Relationship of Pediatrics to General Medicine" (4). He proposed the radical idea that medical care for children should be guided by the special physiology of the infant and child and by understanding the physiologic actions of treatments. With his address, he set the stage for the concept that children are not little adults. He wrote, "Pediatrics does not deal with miniature men and women, with reduced doses and the same classes of diseases in smaller bodies, but .... it has its own independent range and horizon.... There is scarcely a tissue or an organ which behaves exactly alike in the different periods of life.... There are anomalies and diseases which are encountered in the infant and child only. There are those which are mostly found in children, or with a symptomatology and course peculiar to them." Jacobi also stressed the importance of nutrition, prevention of disease, and the role of the physician in public affairs-all still relevant today. For lovers of medical history, Jacobi was an amazing man. He was a prolific speaker and writer, whose collected essays, addresses, and scientific papers were published in an eight-volume collection in 1909 (5).

The early years of the APS were a period with high infant and childhood mortality. The rapid growth of American cities outpaced the ability to provide clean water and sanitation, and poverty was acknowledged to have a major impact on health. Urbanization, discussed today in the global context, was a pressing issue in the United States at the end of the 19 th century. This was an era when women did not yet have the vote and when education and social status of women was generally low (6). Vital statistics were not uniformly collected, so rates of disease and mortality are only estimates. Fertility was high, with an estimated four births per woman; women received no or inadequate prenatal care; "puerperal" infections were common in maternity hospitals; and maternal mortality was high. At the turn of the century, the US neonatal mortality 
rate was estimated at $\sim 60 / 1,000$, the infant mortality rate was $\sim 160 / 1,000$, and the under-five mortality was $\sim 175 / 1,000$. Infectious diseases, including diarrhea, pneumonia, influenza, scarlet fever, tuberculosis, typhoid fever, and pertussis, as well as congenital problems, were the most common causes of childhood mortality (6-9).

\section{DECLINE IN MORTALITY}

Over the 125 years of the APS, we have witnessed an impressive reduction in maternal, infant, and childhood mortality rates in this country. Over this time period, the infant mortality rate in the United States fell from $\sim 160$ in 1900 to $\sim 6 / 1,000$ in 2011 (Figure 1) (7-10). The decline in infant mortality over the first half of the 20th century was due to a number of factors, including improved hygiene and living conditions-with water and sewage systems; electricity and refrigeration; improved economic conditions; education of women; declining fertility rates, with greater birth spacing and smaller family size; improved nutrition of mothers and babies, including pasteurization of milk; the discovery and use of antibiotics; and the development of fluid and electrolyte therapy and safe blood transfusion. It is important to note that the marked decline in infant and childhood mortality seen in this period was due more to social and environmental changes than to advances in science and medicine. The decline started before the widespread use of antibiotics to treat infectious diseases, before the development and use of novel drugs to treat childhood disorders, before the widespread introduction of childhood vaccines and, certainly before the development of pediatric surgery or emergency and intensive care technologies.

\section{PERSONAL CAREER STORIES AND LIFE LESSONS}

We learn a lot from stories. Each of our careers is a personal journey that has lessons learned along the way. I would like to share my own career journey as we reflect on US child health in the early years of the APS, the growth of pediatric research, changes in health indices over time, the broader global community with US health in the context of other countries, and the extraordinary future for science and medicine. I entered pediatrics to become an academic general pediatrician, hoping

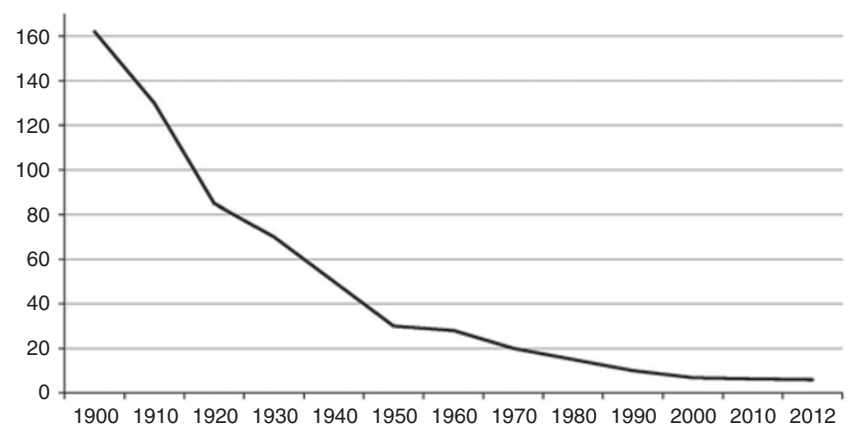

Figure 1. US infant mortality over time: 1900-2012 (per 1,000 live births). Data from refs. 8-10. to spend my career in a hospital setting caring for sick children and studying how to make that care better.

\section{Life Lesson No. 1}

Unexpected opportunities arise in life-explore and embrace them. In my own career, serendipity and life intervened and changed my course. I moved to Atlanta, home to the Centers for Disease Control and Prevention, to follow my husband. A wise mentor, Dr Michael Katz, told me that a good husband was harder to find than a good job, and I left Columbia University and Babies Hospital, institutions that I loved-and a career in general pediatrics-for parts unknown. I trained in neonatology at Emory because of a chance meeting with Dr Al Brann. Dr Brann was a child neurologist by training who studied hypoxic-ischemic encephalopathy in primates in Puerto Rico, was dismayed by the lack of interventions to improve outcomes for babies, and went on to study newborn medicine with Dr Mildred Stahlman at Vanderbilt. He brought the new discipline of neonatal-perinatal medicine to Atlanta and to Emory. I was mesmerized by Dr Brann's commitment to health equity and by his single-minded passion to improve the health and well-being of mothers and babies - a passion that continues to this day-both in the United States and abroad.

\section{Life Lesson No. 2}

Find good mentors-learn from them and with them, and keep connected to them throughout your career. I have had the good fortune to have several extraordinary mentors-people who unselfishly guided me over many years and whom I continue to consult with and admire. They include Dr Michael Katz, former director of Research at the March of Dimes, who was my chair during residency and became a life-long godfather; Dr Brann, my division chief during fellowship and the person who most taught me to be a complete physician; and Dr Andre Nahmias, former chief of Pediatric Infectious Diseases at Emory, who continues to teach me about science and the wonder of discovery.

I entered training in neonatology in the early days of randomized controlled trials and other rigorous studies in neonatal-perinatal medicine. In obstetrics, many strategies that are standard of care today were not in routine use, including noninvasive methods of fetal surveillance, periconceptional folate for reduction of neural tube defects, antenatal steroids for lung maturation in cases of impending preterm delivery, and intrapartum antibiotics to reduce vertical transmission of group B streptococcal infections. In neonatology, this was the presurfactant era, with the scourge of very severe respiratory distress syndrome. We had no advanced ventilatory strategies and no extracorporeal membrane oxygenation. Adult surgeons were still operating on children, even newborns and we could not even imagine fetal surgery. We knew relatively little about optimal nutrition for very low birth weight (LBW) infants, and we had no interventions to improve outcomes for term infants with hypoxic-ischemic encephalopathy and dismal prognosis. In 1980, the US neonatal mortality rate was 6.5/1,000 live births, with very high LBW mortality and racial, ethnic, and 
geographic differences in mortality (11). Short-term and longterm outcomes of preterm infants were guarded. As a young trainee, I was confronted with a personal ethical dilemma related to health disparities, with the marked black/white differences in rates of prematurity/LBW and neonatal mortality; as well as the uncertain outcome of the tiny preterm infant born at the limits of viability-still issues for discussion today.

\section{BANGLADESH THEN AND NOW}

My personal journey continued with the opportunity to live and work in Bangladesh at the International Center for Diarrheal Disease Research, Bangladesh. Unlike today, when we embrace global health opportunities, at the time it was unusual to leave American academia for a position in a developing country. My professors cautioned that I was "throwing away a promising academic career" by leaving the United States. I spent 4 years in Bangladesh that were life changing and provided an important "early childhood exposure" to issues of child survival and mortality throughout the world. There were many lessons learned in this developing country to bring back home. The years in Bangladesh expanded my worldview and taught me, first hand, about maternal and neonatal mortality in settings without intensive care units, about the interconnection between infant mortality and family size, about the importance of the health and well-being of the mother to child survival and family wellbeing, about the impact of malnutrition and the association of nutrition and infection, about vaccine-preventable diseases I had never seen in the United States, and about the social determinants of health - including poverty, poor education and low social status of women. Perhaps most important, I learned that simple interventions could have a measurable impact on infant and child health and survival (12).

Bangladesh was only a plane ride away, but in 1980 the health status of women and children in Bangladesh mirrored that of women and children in the United States at the turn of the 20th century, the early days of the APS. In 1980, maternal mortality was high, linked in part to young age at first birth and high fertility. Most births occurred at home, with deliveries performed by untrained attendants in unhygienic settings. Emergency obstetrical services were limited, and the major causes of maternal death were eclampsia, hemorrhage, and sepsis. Women and girls were stymied by illiteracy and low social status. Neonatal, infant, and under-five mortality rates were astronomical. LBW was common, and there were high rates of infant and childhood malnutrition. Promotion of infant formula threatened exclusive breastfeeding in a country with high rates of diarrheal disease mortality. The World Health Organization Expanded Programme on Immunization had just begun to introduce childhood vaccines into Bangladesh, a country plagued by high rates of vaccine-preventable diseases, including neonatal and maternal childbirth-associated tetanus. If we look at actual health indicators, it is striking how similar Bangladesh in 1980 was to the United States at the turn of the 20th century (Table 1$)(8,9,13-15)$.

As a trainee, before I considered moving to Bangladesh, I was asked to write a review article on tetanus. Very flattered to be asked, I of course said yes - and wrote a review-having never seen a case of tetanus. In 1980, Bangladesh had one of the highest rates of neonatal tetanus in the world, with over 1,000 cases reported that year. In 2011, fewer than 100 cases of neonatal tetanus were reported (a 90\% decline), in large measure due to maternal tetanus immunization (16). One of the great successes of the past 125 years is that most of our American trainees only read about many infectious diseases that were common in 1980, including tetanus, diphtheria, Haemophilus influenzae, and polio. Perhaps most remarkable are the impressive gains in neonatal, infant, and under-five mortality, as well as other indices of maternal and child health, that occurred in Bangladesh over the past 30 years. Bangladesh is now on track to meet several of the United Nations 2015 Millennium Development Goals related to child mortality (Millennium Development Goal 4) and maternal health (Millennium Development Goal 5), including the maternal, infant and under-five mortality targets; the percentage of children immunized against measles; and the percentage of women using contraception (Table 2) $(15,17)$. Bangladesh's steady decline in neonatal, infant, and under-five mortality over time is truly impressive.

What happened in Bangladesh over the past 30 years parallels what happened in the United States in the first half of the 20th century. The reduction in maternal and child mortality is directly linked to social and economic development

Table 1. Health indicators: United States 1900 vs. Bangladesh 1980

\begin{tabular}{lcc}
\hline & US & Bangladesh \\
\cline { 2 - 3 } & 1900 & 1980 \\
\hline Life expectancy at birth & 47 & 55 \\
Birth rate per 1,000 & 30 & 43 \\
Maternal mortality rate per 1,000 & 6 & 5 \\
Neonatal mortality rate per 1,000 & 60 & $52^{\mathrm{a}}$ \\
Infant mortality rate per 1,000 & 160 & 130 \\
Under-five mortality rate per 1,000 & 175 & 193 \\
Birth registration & No & No \\
\hline
\end{tabular}

a1990 Data from Wegman 2001 (ref. 8), Morbidity and Mortality Weekly Report 1999 (ref. 9), Unicef 2012 (refs. 13,15), World Health Organization 2012 (ref. 14).

Table 2. Bangladesh: impressive gains—on track to meet Millennium Development Goals for child mortality and maternal health

\begin{tabular}{lccc}
\hline & $\begin{array}{c}\text { Base year } \\
(1990)\end{array}$ & Current & $\begin{array}{c}\text { MDG target } \\
\text { by 2015 }\end{array}$ \\
\hline Infant mortality/1,000 & 92 & 37 & 31 \\
Under-five mortality/1,000 & 146 & 46 & 48 \\
Measles immunization (\%) & $54 \%$ & $85 \%$ & $100 \%$ \\
Maternal mortality/100,000 & 574 & 194 & 143 \\
Contraceptive use (\%) & $40 \%$ & $62 \%$ & $72 \%$ \\
Births with skilled attendant (\%) & $5 \%$ & $27 \%$ & $50 \%$ \\
\hline MDG, Millennium Development Goal. & \multicolumn{3}{|}{} \\
Unicef 2012 (ref. 15). MDG: Bangladesh Progress 2011 (ref. 17).
\end{tabular}


as well as to improvements in care. Notable factors include improved economic conditions, with better hygiene and living conditions; education of girls and employment of women; family planning with decreased family size; improved access to antenatal care and safe delivery; improved nutrition of mothers and babies; oral rehydration therapy to prevent diarrheal deaths; the recognition and treatment of sick infants; and increased vaccine coverage and decreased vaccine-preventable diseases. I learned first hand the importance of disease surveillance and novel diagnostic tests by starting the Dhaka Hospital Surveillance system at the International Center for Diarrheal Disease Research, Bangladesh (18). This systematic sample of all patients coming to Dhaka Hospital continues to date and has been a unique resource for clinicians, epidemiologists, and investigators. It has served as a starting point for research at Dhaka Hospital to describe the relative importance of enteric pathogens, to identify new and emerging pathogens, to evaluate new diagnostic tests and new therapies, and to design strategies for disease prevention. I was fortunate to have worked in Bangladesh when oral therapy was being implemented on a large scale-and to have witnessed translational science at its best. This simple, but life-saving, therapy was a direct result of taking basic science to the bedside, translating scientific knowledge into a simple therapy, and using public health skills to disseminate therapy broadly. In 1978, an editorial in The Lancet called oral rehydration therapy, "Potentially the most important medical advance of the 20th century" (19). Since that time, countless lives have been saved by oral rehydration therapy, estimated to be approximately a million lives per year.

In Bangladesh and other poor countries, simple low-tech interventions are proving successful at reducing maternal and neonatal mortality. These include antenatal care coverage and having a skilled attendant at delivery; maternal tetanus immunization; prevention of maternal-to-infant transmission of HIV; availability of emergency obstetric care, with cesarean delivery and neonatal resuscitation; temperature control for the newborn, including Kangaroo mother care; early and exclusive breastfeeding; and identification of the sick newborn, with initial stabilization and transfer to an appropriate level of care. Lessons learned in Bangladesh have resonated over the years as I have considered interventions to improve child health in our own country. As pointed out in a recent Lancet article, "Health solutions developed in Bangladesh are saving lives around the world" (20). Perhaps the most important lesson is that positive change is possible-sometimes in populations and areas of the world where you would least expect optimism. I would urge you to take a look at the Gates Foundation website for the "Living Proof Project" that highlights wonderful examples of children and families who are living proof that progress is being made (21).

My own career continued with a brief detour working in basic science laboratories in Sweden and the United States with groups that focused on mucosal immunology and the development of monoclonal antibodies. My time in the lab taught me to respect the rigor, patience, commitment, and discipline of a lab-based researcher. After 4 years in Bangladesh, learning first hand about many infectious diseases, and after 3 years working in the laboratory-I returned to my roots in neonatology - with a newfound interest in neonatal infectious diseases, neonatal clinical trials, and global child survival.

\section{CHANGES IN OBSTETRICAL AND NEONATAL CARE OVER TIME}

The past two and a half decades have been a remarkable period for both maternal and neonatal care in the United States. The fields of maternal fetal medicine and neonatology blossomed during these years. The diagnostic modalities, prevention strategies, and acute care interventions and technologies that are routine in the United States today were developed during those years. These advances were driven by laboratory discoveries and translation to novel therapies, by development of new drugs and devices, by clinical trials, by disease surveillance, and by public health interventions.

The National Institute of Child Health and Human Development (NICHD)-sponsored Maternal Fetal Medicine and Neonatal Research Networks were started to improve the rigor of clinical research and clinical trials in neonatal-perinatal medicine. Their goal is to address common problems in obstetrics and neonatology, to train physician scientists in clinical trials methodology, and ultimately to improve care for mothers and babies. Similar to other research networks, including the Children's Oncology Group, the Severe Asthma Research Program, and the Pediatric Heart Network, these networks foster a culture of participation in clinical trials and a mindset that research saves lives. Over the past 25 years, these networks have conducted numerous collaborative epidemiologic studies and clinical trials that have contributed to the evidence base that has changed how we care for mothers and newborns. They have enormous potential that could be enhanced by expansion of clinical sites and by the ability to conduct longer-term follow up of high-risk newborns. Good news-the US neonatal mortality rate has declined by a third since 1980 , with even larger reductions in deaths among very LBW preterm infants (Table 3) (11,22). The increased and impressive survival rates for even the most immature preterm infants, underscore the need to move beyond survival to identifying interventions to improve long-term health, nutrition, and neurodevelopmental outcomes for these vulnerable babies (23). This good news is tempered by a continued black-white disparity in both neonatal and infant mortality rates, with black infants having twice the rates of neonatal and infant deaths as compared with white

Table 3. US neonatal mortality rates per 1,000 live births

\begin{tabular}{lrr}
\hline Birth weight $(\mathrm{g})$ & 1980 & 2009 \\
\hline $500-1,499$ & 380.78 & 201.42 \\
$1,500-2,499$ & 24.08 & 7.91 \\
$2,500-3,999$ & 2.14 & 0.73 \\
$4,000+$ & 1.86 & 0.54 \\
Total & 6.52 & 4.18 \\
\hline
\end{tabular}

Buehler et al., Public Health Reports 1987 (ref. 11). Mathews et al., National Vital Statistics Reports 2013 (ref. 22). 
infants (Table 4) (10). We are not given the luxury to choose our parents. Most pediatricians would agree that the socioeconomic or racial circumstances of an infant's birth should not determine the health outcomes of that child. Prematurity is the single greatest cause of neonatal and infant death in the United States. Although only $3.5 \%$ of births in the United States occur before $34 \mathrm{wk}$ gestational age, $57 \%$ of infant deaths occur among infants born at these early gestational ages (Figure 2) (22). Sobering news is that the United States continues to have high rates of preterm birth, with continued racial disparity in risk of prematurity (Figure 3) (24).

\section{THE UNITED STATES IN AN INTERNATIONAL PERSPECTIVE}

The Institute of Medicine recently released a study, "US Health in International Perspective: Shorter Lives, Poorer Health" (25). When compared with other high-income countries in the world, the US fares worse in nine health domains, including adverse birth outcomes. The US ranks lower than other high-income countries in several indexes of maternal and neonatal health. The rates of stillbirth, neonatal mortality, maternal mortality, and the percentage of LBW are all higher in the United States than in many other peer countries. We rank last among 17 peer countries in infant mortality, with the gap widening in recent years (25).

Prematurity is the leading cause of infant death throughout the world. Almost half the states in the United States received a grade of $\mathrm{C}$ or worse on a national report card for preterm births. When we consider the United States in the context of European countries, the high US preterm birth rate is the greatest driver of our poor infant mortality in comparison to other countries. Racial differences in US infant mortality also

Table 4. Racial disparity in US neonatal and infant mortality rates

\begin{tabular}{lcccccccc}
\hline & \multicolumn{3}{c}{1980} & & \multicolumn{3}{c}{2011} \\
\cline { 2 - 5 } \cline { 7 - 8 } \cline { 6 - 8 } & Total & Black & White & & Total & Black & White \\
\hline NMR & 6.52 & 10.6 & 5.68 & & 4.04 & 7.45 & 3.45 \\
IMR & 12.6 & 22.2 & 10.9 & & 6.05 & 11.42 & 5.11 \\
\hline
\end{tabular}

Hoyert et al., National Vital Statistics Report 2012 (ref. 10). Buehler et al., Public Health Reports 1987 (ref. 11). IMR, infant mortality rate; NMR, neonatal mortality rate.

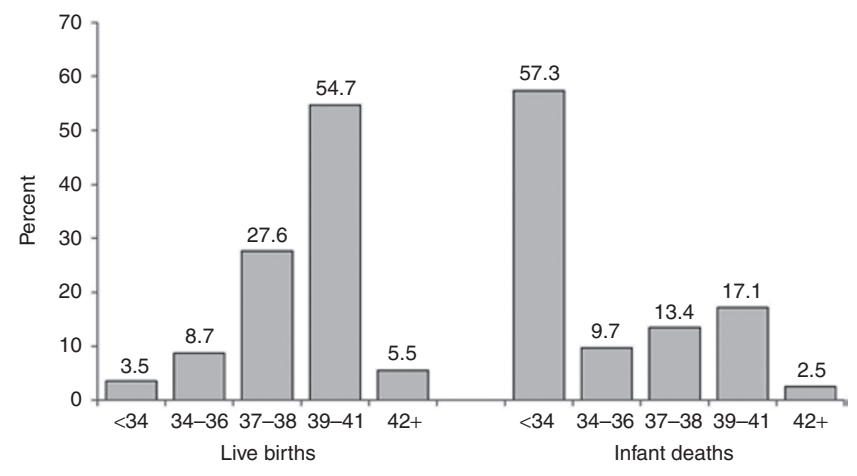

Figure 2. Percentage distribution of live births and infant deaths by gestational age in the United States, 2009. Data from ref. 22. contribute to our poor international rankings. These comparisons underscore the need to decrease the unacceptably high rates of prematurity and LBW in the United States and to close the racial and ethnic gap. A Lancet editorial following release of the Institute of Medicine report chastised us, "The USA is one of the world's wealthiest countries; it should be one of the world's healthiest" (26). We certainly have an obligation to do more to close the gap. As investigators, we need to frame the full scope of research as a social contract to improve health through scientific discovery, innovation, and application. The Institute of Medicine report cited the surgeon general's national prevention strategy as one means to help close this US/international gap. Similar to what we have seen in Bangladesh, this strategy involves implementing simple low-tech interventions to improve the public's health. "Healthy People" is a US government program that provides 10 -year evidence-based national objectives for improving the health of all Americans. For more than 3 decades "Healthy People" has established benchmarks and monitored progress. The Healthy People 2020 targets include improvement of 71 health indicators in maternal and child health, with focus areas of morbidity and mortality, maternal health, infant care, disability, and health services (27). We know that simple interventions work. The challenge is, can we meet the 2020 targets? Health services research will help us better understand how to implement these interventions to make a measurable impact on the public's health.

\section{CAREER LESSONS}

As I reflect on science, pediatrics, and child health over the course of a career that has spanned work in several different countries, from low-technology low-resource settings to hightechnology high-resource settings, a number of themes emerge (Table 5). First off-research saves lives. We have innumerable examples, from oral rehydration therapy in developing countries to artificial surfactant in neonatal intensive care units in developed countries. The thrill of discovery is infectious. For the trainees and young faculty in the audience, find something you can become passionate about and work on it for the long haul. Do not be impatient. Success in the lab and then translating science to improved care and outcomes takes a long time. The future success of science and child health depends on a continuous pipeline of young scientists interested in pediatrics

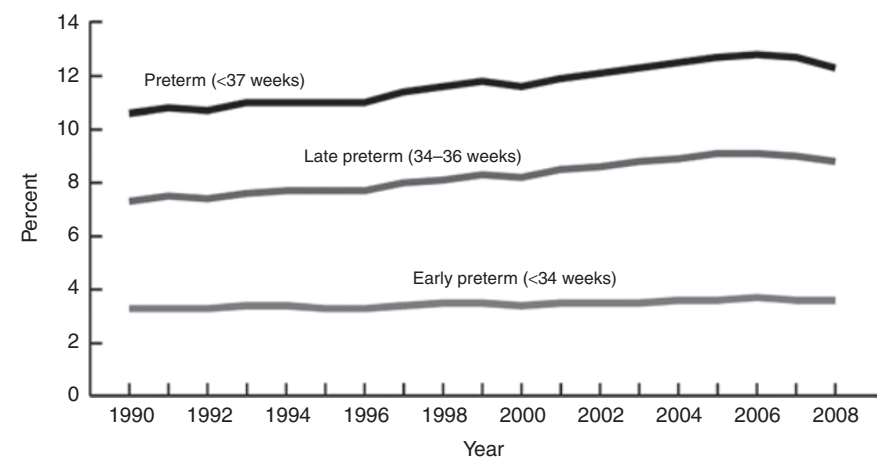

Figure 3. US preterm birth rate over time. Data from ref. 24. 
Table 5. Science, pediatrics, child health

- Research saves lives

- The thrill of discovery is infectious

- The future depends on young scientists interested in child health

- Rigorous high-quality research training is critical

- Need support of policy makers and funders to ensure translation of scientific discoveries into improved health

- Health is a human right. We have a moral imperative to close the gap between rich and poor-in the United States and abroad

- Abraham Jacobi was right: physicians and scientists have an obligation to be involved in public policy

and child health. Long-term sustainable funding for pediatric research training needs to be a US priority. The (US) National Institutes of Health (NIH)-sponsored Pediatric Scientist Development Program, the NICHD Child Health Research Centers, and the Robert Wood Johnson Clinical Scholars program are wonderful examples of programs that provide rigorous high-quality research training and start trainees off on a strong footing in a very competitive scientific world. Engaging the support of policymakers and funders is essential to ensuring we can translate scientific discoveries into improved health. Health is a human right. We have a moral obligation to use science for the public good and to close the gap between rich and poor-in the United States and abroad. Abraham Jacobi was right 125 years ago-physicians and scientists have an obligation to be involved in public policy.

\section{FISCAL CONCERNS BUT REASONS FOR OPTIMISM}

The current financial climate, with the threat to governmentfunded services for children and government research funding adds a sobering note. For the past decade, the NIH budget has been relatively flat in total dollars, even before cuts mandated by sequestration. This reflects a decline in true funding ability and has resulted in a decline in percentage success rate for research grants. We live in a difficult world for established investigators and one that is a real threat to new investigators - the future of pediatric research. NIH funding for pediatric research, $\sim \$ 3.3$ billion or $10 \%$ of all NIH funding, is spread across all institutes, with most funding coming from NICHD. In his APS presidential address in 1979, Dr Norman Kretchmer, director of NICHD at the time, wrote: "As director of an institution that funds most of the pediatric and obstetric research in the United States, I feel a deep anxiety about the future of knowledge-building activities in this country, and I know that I am not alone in my concern. Within the past decade, all of us have perceived a hardening of public attitudes toward scientific research, reflected in declining fiscal support from the government" (28). He went on to make an impassioned plea for members of the APS to become strong advocates for pediatric science. Kretchmer's comments are relevant to today's debate over research funding and overall funding for children.

Despite today's fiscal crisis, we have many reasons to be optimistic (Table 6). With over 7,000 physicians and scientists attending the Pediatric Academic Societies meeting this year,
Table 6. Reasons to be optimistic

- High interest in pediatric research

- Exciting areas of science and technology with applications for child health

- Influential funders paying attention to child survival

- Health targets and metrics being monitored and progress documented

- The gap between rich and poor countries is narrowing

- Mobile technology and enhanced communication

- New focus on pediatric antecedents of chronic disease

- Pediatric research matters and makes a difference

pediatric research and training are alive and well. Exciting advances in science and technology can dramatically change child health and disease. Many new areas of science and technology have applications for child health, including nanotechnology, the "omics" revolution, advanced imaging, complex computing, and genetic understanding of health and disease and their intersection with the exposome and the microbiome. We need to take best advantage of advances in science to translate new discoveries into better health for mothers and children. Bill Gates has challenged us to use "the power of innovation to reduce hunger, poverty and disease" (29). Influential international funders, such as the Gates Foundation, have paid increased attention to child survival throughout the world, with special attention to resource-poor countries. We need to learn from data, and learn to collect and monitor the right data. The Millennium Development Goals and the Healthy People targets have defined and monitored changes over time. The gap between rich and poor is narrowing-our challenge is to close that gap. The information revolution of electronic health records, mobile technology, and increased access to medical information will allow us to enhance communication among providers and with patients and families and to implement interventions to improve individual and public health. With increasing understanding of the pediatric antecedents of adult chronic disease, child health and attention to the life course will become increasingly important. I am optimistic that these challenges will be met by the physicians and scientists at the Pediatric Academic Societies meeting this year, people with a passion to make a difference in the lives of mothers and children.

\section{REFLECTIONS ON APS AT 125}

We have seen amazing advances in science and medicine over the past 125 years. Morbidity and mortality from acute infectious diseases have declined, with a shift in the epidemiology of pediatric disease to more chronic conditions. Moreover, many diseases that were once fatal in early childhood have become more manageable chronic illnesses. One hundred and twentyfive years after our founding, APS is thriving. Our mission remains to "advance academic pediatrics." The APS Strategic Plan was revised in 2012 to articulate core values and to define four strategic domains for action.

In our 125 years, APS has grown from 43 founding members who were all men, to almost 2,000 members, with one-quarter 
women. We have had 122 presidents, only nine of whom were women. Despite last year's APS presidential address "Mind the Gap," we know little about the diversity of our members (30). From its beginning, our specialty has been interested in the whole child. This holistic approach has encouraged pediatricians and child health researchers to view health and disease in the context of their relationship to social and environmental, as well as scientific or genetic, determinants of disease. At the 50th anniversary celebration of NICHD this past year, Dr Duane Alexander, former director said, "There are 2 ways to assess the impact of research and public health interventions: changes in health indicators and changes in people's lives. Research in child health has changed both" (31). The APS represents the senior leadership of academic pediatrics. We have an obligation to use our collective influence to expand efforts to advocate on behalf of children-for access to high quality health care and for enhanced funding for child health research and pediatric research training. Pediatric research matters and makes a difference.

\section{REFERENCES}

1. Stern AM, Markel H. Formative Years: Children's Health in the United States 1880-2000. Ann Arbor, MI: The University of Michigan Press, 2002.

2. Pearson HA. The Centennial History of the American Pediatric Society 1888-1988. North Haven, CT: EH Roberts, 1988.

3. Halpern SA. American Pediatrics: The Social Dynamics of Professionalism, 1880-1980. Berkeley, CA: University of California Press, 1988.

4. Jacobi, A. The relation of pediatrics to general medicine. Trans Am Pediatric Soc, 1889;1: 15-7.

5. Robinson WJ. Collectanea Jacobi: Collected Essays, Addresses, Scientific Papers, and Miscellaneous Writings of A. Jacobi. New York: The Critic and Guide Company, 1909.

6. Meckel RA. Save the Babies: American Public Health Reform and the Prevention of Infant Mortality 1850-1929. Baltimore, MD: Johns Hopkins University Press, 1990.

7. Guyer B, Freedman MA, Strobino DM, Sondik EJ. Annual summary of vital statistics: trends in the health of Americans during the 20th century. Pediatrics 2000;106:1307-17.

8. Wegman ME. Infant mortality in the 20th century, dramatic but uneven progress. J Nutr 2001;131:401S-8S.

9. Achievements in Public Health, 1900-1999: Healthier Mothers and Babies. MMWR 1999;48:849-58.

10. Hoyert DL, Xu J. Deaths: preliminary data for 2011. Natl Vital Stat Rep 2012;61:6.
11. Buehler JW, Strauss LT, Hogue CJR, Smith JC. Birthweight-specific causes of infant mortality, United States, 1980. Public Health Reports 1987;102:162-71.

12. Stoll BJ, Measham AR. Children can't wait: improving the future for the world's poorest infants. J Pediatr 2001;139:729-33.

13. Child Info: Monitoring the situation of children and women, UNICEF 2012. (http://www.childinfo.org/mortality_tables.php).

14. Bangladesh Child Health Profile, WHO 2012. (http://www.who.int/maternal_child_adolescent/data/media/cah_chp_bangladesh.pdf).

15. Levels and Trends in Child Mortality, Unicef 2012. (http://www.who. int/maternal_child_adolescent/documents/levels_trends_child_mortality_2012.pdf).

16. Achieving and Sustaining Maternal and Neonatal Tetanus Elimination: Strategic Plan 2012-2015. WHO 2012. (http://www.who.int/immunization_monitoring/MNTEStrategicPlan_E.pdf).

17. The Millennium Development Goals Bangladesh Progress Report 2011. (http://www.undp.org.bd/info/pub/MDG\%20Progress\%20Report\%2011. pdf).

18. Stoll BJ, Glass RI, Huq MI, Khan MU, Holt JE, Banu H. Surveillance of patients attending a diarrhoeal disease hospital in Bangladesh. Br Med J (Clin Res Ed) 1982;285:1185-8.

19. Water with sugar and salt. Lancet 1978;312:300-1.

20. Yee A. Profile: ICDDR,B - Saving lives in Bangladesh and beyond. Lancet 2013;381:1350.

21. Living Proof. (http://www.one.org/livingproof/en/).

22. Mathews TJ, MacDorman MF. Infant mortality statistics from the 2009 period linked birth/infant death data set. Natl Vital Stat Rep 2013;61:8.

23. Stoll BJ, Hansen NI, Bell EF, et al.; Eunice Kennedy Shriver National Institute of Child Health and Human Development Neonatal Research Network. Neonatal outcomes of extremely preterm infants from the NICHD Neonatal Research Network. Pediatrics 2010;126:443-56.

24. Martin JA, Osterman MJ, Sutton PD. Are preterm births on the decline in the United States? Recent data from the National Vital Statistics System. NCHS Data Brief 2010;39:1-8.

25. Woolf SH, Aron L. U.S. Health in International Perspective: Shorter Lives, Poorer Health. Washington, DC: Institute of Medicine, National Academies Press, 2013.

26. Wealth but not health in the USA. Lancet 2013;381:177-8.

27. Healthy People 2020. (http://www.healthypeople.gov/2020/about/default. aspx).

28. Kretchmer N. Science and Scholarship in Pediatrics. Presidential Address, American Pediatric Society, 1979. Pediatr Res 1980;14:1093-6.

29. Gates B. 2013 Annual Letter. (http://annualletter.gatesfoundation.org/).

30. Stapleton BF. American Pediatrics Society 2012 Presidential Address: mind the gap. Pediatr Res 2012;72:441-3.

31. Alexander DF. Why should there be an NICHD? Pediatrics 2011;127: $325-33$. 